\title{
Fasting Glycaemia Is A Predictor Of Outcome After Acute Myocardial Infarction
}

\author{
Shofiullah ${ }^{1}$, Ismail Patwary ${ }^{2}$, Matiur Rahman ${ }^{3}$, Shahabuddin ${ }^{4}$. \\ ${ }^{1}$ Registrar, Medicine. ${ }^{2}$ Professor \& Head of Department of Medicine. ${ }^{3}$ Associate Prof. of Neurology. ${ }^{4}$ Associate Prof. \& Head of Department of \\ Cardiology. Sylhet MAG Osmani Medical College Hospital, Sylhet.
}

\begin{abstract}
:
Background: Patients with recent myocardial infarction have an increased incidence of impaired fasting glucose (IFG) and new-onset diabetes. There is a clear relationship between elevated fasting glucose during acute myocardial infarction and increased mortality and morbidity risk. Objective: To find out the impact of fasting glycaemia as a predictor of outcome of patients with acute myocardial infarction. Methods: A total of 102 patients with acute myocardial infarction of first attack were selected according to inclusion and exclusion criteria. Fifty-one patients with acute myocardial infarction having fasting hyperglycaemia were enrolled as case group and another 51 patients with acute myocardial infarctions having fasting euglycaemia were enrolled as control group. Results : Among the diabetic patients , acute left ventricular failure (ALVF) developed in $22(68.8 \%)$, arrhythmias in $5(16.6 \%)$ and cardiovascular mortality in $8(25.0 \%)$ patients ; it was $7(36.8 \%), 4(21.1 \%)$ and $4(21.1 \%)$ respectively in IFG patients; and $7(13.7 \%), 4(7.8 \%)$ and $2(3.9 \%)$ respectively in euglycaemia patients. Acute left ventricular failure and 30 days CV mortality significantly differed among the groups ( $<<0.001$ and $p=0.015$ respectively). But no significant difference in arrhythmias $(p=0.284)$. Conclusions: The patients of impaired fasting glucose (IFG) and diabetes mellitus both were predictor for in hospital heart failure (ALVF) and 30-day cardiovascular mortality as compared to euglycaemia.
\end{abstract}

Key words: Fasting hyperglycaemia, acute myocardial infarction, cardiovascular morbidity and mortality.

[BSMMU J 2013; 6 (2): 135-140]

\section{Introduction :}

Diabetes is an established risk factor for cardiovascular disease, and the risk of cardiovascular disease increases with worsening hyperglycaemia .,2 Furthermore, coronary artery disease is the most common cause of death in patients with diabetes. ${ }^{3}$ Patients with coronary artery disease and a recent myocardial infarction or acute coronary syndrome (ACS) have an increased incidence of impaired fasting glucose (IFG) and new-onset diabetes ${ }^{4-6}$ Although the mechanisms underlying this association are not fully understood. In patients who have had recent myocardial infarction, the lack of insulin associated with hyperglycaemia may lead to a decrease of glycolytic substrate for cardiac muscle and excessive free fatty acids ${ }^{7}$ These changes may reduce myocardial contractility at

Address for Correspondence: Dr.Mohammad Shofiullah.

Head of Department of Cardiology. Sylhet MAG Osmani Medical College Hospital Sylhet.Email: shofiullahmohammad@yahoo.com.sg. Mobile no.01711101711 increased oxygen cost, lead to pump failure, and promote arrhythmias.$^{8}$ Several studies have also documented a clear relationship between elevated fasting glucose during acute myocardial infarction and increased mortality risk .$^{9-12}$ Unlike the random glucose level on admission, IFG may be a better reflection of abnormalities in underlying glucose metabolism, and thus may be a better predictor of both short-term and long- term outcomes. In one of the earlier studies on this issue, Suleiman et al. ${ }^{9}$ demonstrated that while both admission and fasting glucose levels predicted 30-day mortality in non-diabetic patients with acute myocardial infarction, fasting glucose was the better discriminator. There was no study in Bangladesh regarding the relationship between fasting plasma glucose level and complications after acute myocardial infarction including mortality. So, this study was designed to find out the impact of fasting glycaemia as a predictor of outcome of patients with acute myocardial infarction in Bangladeshi patients at Sylhet. 
outcome of patients with acute myocardial infarction in Bangladeshi patients at Sylhet.

\section{Methods :}

This was a prospective comparative study done in the Department of Cardiology, Sylhet MAG. Osmani Medical College Hospital, Sylhet from 1st July 2008 to 30th June 2010. All patients having acute myocardial infarction were considered as study population. Fifty-one acute myocardial infarction patients having fasting hyperglycaemia (diabetes mellitus and IFG) were enrolled as study group and 51 acute myocardial infarction patients having fasting euglycaemia were enrolled as control group.

Before enrollment in this study informed written consent was obtained from the patients after full explanation of the purpose of the study. They were informed of their right to withdraw from the study at any stage.

\section{Procedure of Data Collection:}

A detailed history and thorough physical examination was done in each patient on admission. Criteria for myocardial infarction was any two of the following: cardiac chest pain lasting at least 30 minutes; $1 \mathrm{~mm} \mathrm{ST}$ elevation in at least one standard lead or $2 \mathrm{~mm} \mathrm{ST}$ elevation in two or more contiguous chest leads; or Serum troponin I (higher than the upper limit of reference range). ${ }^{11,14}$ Data on demographics, cardiovascular risk factors, and medical history were collected along with baseline clinical data and admission data like systolic blood pressure (SBP) ,diastolic blood pressure (DBP) and heart rate. Echocardiography was performed at day 3 to calculate left ventricular ejection fraction (LVEF). Data on acute reperfusion procedures- thrombolysis and primary coronary intervention (PCI) was collected. The outcomes were defined as in-hospital heart failure, ventricular arrhythmia (ventricular tachycardia or ventricular fibrillation). In-hospital heart failure was defined as rales over more than half of the lung field (Killip class II), pulmonary oedema (Killip class III), or cardiogenic shock (Killip class IV). ${ }^{11}$

Friedwald's formula, LDL $=($ T.Chol - HDL-C $)-T G / 5$ when the values of TG were less than $400 \mathrm{mg} \% .15$ Relevant findings were recorded by using a pretested structured data collection sheet designed for the study. The patients were followed up

up to 30 days in the cardiology department. Communication with the patient's attendants was maintained over mobile phone as recorded in the research instrument.

Data were processed and analyzed with the help of computer program SPSS 16.0 version for windows. All continuous data tested were expressed as mean and standard deviation. Comparisons of continuous variables between the groups of patients were performed by ' $Z$ ' test. Qualitative data were expressed as frequency and percentages; and comparison was done by the Chi-Square (X2) test or Fisher's Exact test. Logistic regression analysis was done to find out relationship between different levels of glycaemia \& outcome. (P) value of less than $5 \%$ $(p<0.05)$ was considered statistically significant.

All information was collected confidentially with complete respect to the patient's wish and without any force or pressure. Patient's rights were preserved according to Helsinki declaration.

\section{Table-I}

Base line characteristics of the patients $(n=102)$

\begin{tabular}{llcc}
\hline & $\begin{array}{l}\text { Hypergly } \\
\text { caemic } \\
\text { group } \\
(\mathrm{n}=51)\end{array}$ & $\begin{array}{c}\text { Eugly } \\
\text { caemic } \\
\text { group } \\
(\mathrm{n}=51)\end{array}$ & $\begin{array}{c}\mathrm{p} \\
\text { value }\end{array}$ \\
\hline Age in Years & $52.51 \pm 10.97$ & $49.82 \pm 10.96$ & $>0.05^{*}$ \\
Age group & & $18(35.3)$ & $0.156 \dagger$ \\
$\leq 40$ years & $8(15.7)$ & $11(21.5)$ & \\
$41-50$ years & $17(33.3)$ & $14(27.5)$ & \\
$51-60$ years & $18(35.3)$ & $3(5.9)$ & \\
$61-70$ years & $5(9.8)$ & $5(9.8)$ & \\
$\geq 70$ years & $3(5.9)$ & $46(90.2)$ & $0.598 \dagger \dagger$ \\
Sex & & $5(9.8)$ & \\
Male & $41(80.4)$ & & \\
Female & $10(19.6)$ & $44(86.3)$ & $0.425 \dagger \dagger$ \\
Smoking habit & & $7(13.7)$ & \\
Smoker & $41(80.4)$ & & \\
Non-smoker & $10(19.6)$ & &
\end{tabular}


There were $80.4 \%$ male and $19.6 \%$ female in the hyperglycaemic group; while $90.2 \%$ male and $9.8 \%$ female in euglycaemic group.

In hyperglycaemic group, $80.4 \%$ patients was smoker; $19.6 \%$ was non-smoker; whereas in euglycaemic group, $86.3 \%$ patients was smoker and $13.7 \%$ patients was non-smoker.

\section{Table-II}

Distribution of patients according to history of hypertension $(n=102)$

\begin{tabular}{llcc}
\hline Age Group & $\begin{array}{l}\text { Study Group } \\
\text { Hypergly } \\
\text { caemic } \\
\text { group }(\mathrm{n}=51)\end{array}$ & $\begin{array}{c}\text { Euglyc } \\
\text { aemic } \\
\text { Group }(\mathrm{n}=51)\end{array}$ & \\
& $20(39.2)$ & $23(45.1)$ & 0.752 \\
\hline Present & $14(27.5)$ & $11(21.6)$ & \\
Absent & $17(33.3)$ & $17(33.3)$ & \\
Unknown & $51(100.0)$ & $51(100.0)$ & \\
Total &
\end{tabular}

*Chi-Square (X2) Test was applied to analyze the data.

Figure in the parenthesis indicates corresponding percentage.

The difference between the two groups was statistically not significant $(\mathrm{p}=0.752)$.

Table-III

Distribution of patients by complication (30 days) ( $n=102)$

\begin{tabular}{lcccc}
\hline $\begin{array}{l}\text { Short term } \\
\text { complication }\end{array}$ & $\begin{array}{c}\text { DM } \\
(\mathrm{n}=32)\end{array}$ & $\begin{array}{c}\text { IFG } \\
(\mathrm{n}=19)\end{array}$ & $\begin{array}{c}\text { Eugly } \\
\text { caemia } \\
(\mathrm{n}=51)\end{array}$ & $\begin{array}{c}* \mathrm{P} \\
\text { Value }\end{array}$ \\
\hline ALVF & $22(68.8)$ & $7(36.8)$ & $7(13.7)$ & $<0.001$ \\
Arrhythmias & $5(16.6)$ & $4(21.1)$ & $4(7.8)$ & 0.284 \\
$\begin{array}{l}30 \text { days CV } \\
\text { mortality }\end{array}$ & $8(25.0)$ & $4(21.1)$ & $2(3.9)$ & 0.015 \\
\hline
\end{tabular}

ALVF: Acute left ventricular failure CV: Cardiovascular * Chi-Square (X2) Test was applied to analyze the data.

Among the diabetic patients, acute left ventricular failure (ALVF) developed in 22 (68.8), arrhythmias in 5 (16.6\%) and cardiovascular mortality in $8(25.0 \%)$ patients; it was $7(36.8 \%), 4(21.1 \%)$ and $4(21.1 \%)$ respectively in IFG patients; and $7(13.7 \%), 4(7.8 \%)$ and $2(3.9 \%)$ respectively in euglycaemic patients. Acute left ventricular failure and 30 days $\mathrm{CV}$ mortality significantly differed among the groups $(\mathrm{p}<0.001)$ and $\mathrm{p}=0.015$ respectively). But no difference in arrhythmias $(\mathrm{p}=0.284)$.

Table-IV

Fasting glycaemia as a predictor for in-hospital heart failure

\begin{tabular}{|c|c|c|c|c|}
\hline $\begin{array}{l}\text { Glycaemic } \\
\text { status }\end{array}$ & $\begin{array}{l}\text { In-hospital } \\
\text { heart } \\
\text { failure }\end{array}$ & $\begin{array}{c}\text { Odds ratio } \\
(95 \% \text { of } \mathrm{CI}) \\
(\mathrm{n}=36)\end{array}$ & $\begin{array}{c}\text { *P } \\
\text { value }\end{array}$ & $\begin{array}{l}\mathrm{P} \text { for } \\
\text { trend }\end{array}$ \\
\hline Euglycaemia & $7(13.7)$ & 1.00 & & $<0.001$ \\
\hline \multirow[t]{2}{*}{ IFG } & $7(36.8)$ & 3.667 & & \\
\hline & $(1.075-41.257)$ & & 0.038 & \\
\hline \multirow[t]{2}{*}{ DM } & $22(68.8)$ & 13.829 & & \\
\hline & $(4.635-41.257)$ & & $<0.001$ & \\
\hline
\end{tabular}

* Binary logistic regression analysis was applied to analyze the data.

Table-IV: showed the fasting glycaemia as a predictor for in-hospital heart failure. The patients of impaired fasting glucose (IFG) was a predictor for in-hospital heart failure as compared to euglycaemia $(\mathrm{OR}=3.667 ; 95 \%$ of $\mathrm{CI}=1.075-41.257 ; \mathrm{p}=0.038$ ). Diabetes mellitus was also a predictor for in-hospital heart failure as compared to euglycaemia $(\mathrm{OR}=13.829 ; 829 ; 95 \%$ of $\mathrm{CI}=4.635-41.257$; $\mathrm{p}<0.001$ ).

\section{Table-V}

Fasting glycaemia as a predictor for 30 days $C V$ mortality $(n=14)$

\begin{tabular}{lcccc}
\hline $\begin{array}{l}\text { Glycaemic } \\
\text { status }\end{array}$ & $\begin{array}{c}\text { In-hospital } \\
\text { heart } \\
\text { failure }\end{array}$ & $\begin{array}{c}\text { Odds ratio } \\
(95 \% \text { of CI })\end{array}$ & $\begin{array}{c}* \mathrm{P} \\
\text { value }\end{array}$ & $\begin{array}{c}\mathrm{P} \text { for } \\
\text { trend }\end{array}$ \\
\hline Euglycaemia & $\begin{array}{c}2(3.9) \\
\text { IFG }\end{array}$ & $\begin{array}{c}1.00 \\
(21.1)\end{array}$ & 6.533 & 0.037 \\
$(1.087-39.257)$ & 0.040 & & \\
DM & $8(25.0)$ & 8.167 & \\
$(1.609-41.458)$ & 0.011 & & & \\
\hline
\end{tabular}

* Binary logistic regression analysis was applied to analysis the data.

Table-V: showed the fasting glycaemia as a predictor for 30 days CV mortality. The patient with acute myocardial infarction with diabetes mellitus was a predictor for 30 days CV mortality as compared to euglycaemia 
$(\mathrm{OR}=8.167 ; 95 \%$ of $\mathrm{CI}=1.609-41.458 ; \mathrm{p}=0.011)$; while those with IFG was also a significant predictor for 30 days $\mathrm{CV}$ mortality as compared to euglycaemia $(\mathrm{OR}=6.533$; $95 \%$ of $\mathrm{CI}=1.087-39.257$; $\mathrm{p}=0.040$ ).

\section{Discussion :}

In this study the mean age of patients in hyperglycaemic group was 52.5110 .97 years; whereas the mean age of the euglycaemic group was 49.8210 .96 years. The mean age of the patients in both groups was almost identical ( $p>0.05$ ) which is similar to the findings of Vural et al. ${ }^{16}$ where the mean age of myocardial infarction patients was 548 years. In the current study, there were $80.4 \%$ male and $19.6 \%$ female in the hyperglycaemic group; $90.2 \%$ male and $9.8 \%$ female in euglycaemic group. The sex difference between the groups was not statistically significant $(\mathrm{p}=0.598)$. This result was concordance with the study of Barakat et al. ${ }^{17}$ that $87.0 \%$ of Bangladeshi patients with acute myocardial infarction and $70.0 \%$ of white patients were male. Aronson et al. ${ }^{10}$ found $73 \%$ male and $23 \%$ female in the hyperglycaemic group; $84 \%$ male and $16 \%$ female in euglycaemic group of patients with acute myocardial infarction. In this study $80.4 \%$ of patients were smoker and $19.6 \%$ were non-smoker in hyperglycaemic group; whereas in euglycaemic group $86.3 \%$ of patients were smoker and $13.7 \%$ patients were non-smoker. The difference between the two groups was statistically not significant $(\mathrm{p}=0.425)$. This result was supported by Barakat et al.17 that $71.3 \%$ of Bangladeshi immigrants patients and $70.3 \%$ of white patients with acute myocardial infarction were smoker. Vivas et al. ${ }^{18}$ found $84.8 \%$ of their acute coronary syndrome was smoker. In the current study $39.2 \%$ patients had history of hypertension, $27.5 \%$ patients had no history of hypertension and $33.3 \%$ unknown about their blood pressure in hyperglycaemic group; while in euglycaemic group, $45.1 \%$ patients had history of hypertension $21.6 \%$ patients had no history of hypertension and $33.3 \%$ unknown about their blood pressure. The difference between the two groups was statistically not significant $(\mathrm{p}=0.752)$. This result was similar to the study of Barakat et al. ${ }^{17}$ that $43.5 \%$ of Bangladeshi patients and $38.4 \%$ of white patients with acute myocardial infarction had history of hypertension.
In hyperglycaemic group $56.9 \%$ of patients developed acute left ventricular failure; while in euglycaemic group, $13.7 \%$ of patients developed acute left ventricular failure during hospital stay. The patients of hyperglycaemic group compared to that of euglycaemic group was 8.3 times more likely to developed acute left ventricular failure during hospital stay $(\mathrm{OR}=8.286 ; 95 \%$ of $\mathrm{CI}=3.137-21.883 ; \mathrm{p}<0.001)$. This result was almost similar to the study of Verges et al. ${ }^{11}$ that $45.0 \%$ of hyperglycaemic patients developed acute left ventricular failure during hospital stay; while in $13.7 \%$ of euglycaemic patients developed acute left ventricular failure during hospital stay. In hyperglycaemic group, 17.6\% patients developed arrhythmias; while in euglycaemic group, $7.8 \%$ patients developed arrhythmias during hospital stay. The development of arrhythmias during hospital stay in both groups were almost similar $(\mathrm{OR}=2.518 ; 95 \%$ of $\mathrm{CI}=0.722-8.781 ; \mathrm{p}=0.138$ ). This result was consistent with the study of Verges et al. ${ }^{11}$ that $10.8 \%$ of hyperglycaemic patients developed arrhythmias during hospital stay; while in $10.0 \%$ of euglycaemic patients developed arrhythmias during hospital stay.

In hyperglycaemic group $23.5 \%$ patients, while in euglycaemic group $3.9 \%$ patients. had 30 days cardiovascular mortality as compared to that of euglycaemic group. This result was supported by Nua et al. ${ }^{19}$ that $16.0 \%$ patients had cardiovascular mortality in hyperglycaemic group; while no cardiovascular mortality in glycaemic group. Verges et al. ${ }^{11}$ found $9.0 \%$ patients had cardiovascular mortality in glycaemic group.

In the present study the patients of impaired fasting glycaemia (IFG) [(Odd Ration (OR) $=3.667 ; 95 \%$ of confidence interval $(\mathrm{CI})=1.075-41.257 ; \mathrm{p}=0.038)]$ and diabetes mellitus (DM) $(\mathrm{OR}=13.829$; $95 \%$ of $\mathrm{CI}=4.635$ 41.257; $\mathrm{p}<0.001$ ) were a predictor for in-hospital heart failure as compared to euglycaemia. This result was supported by Verges et al. ${ }^{11}$ that both diabetes mellitus $(\mathrm{OR}=1.82 ; 95 \%$ of $\mathrm{CI}=1.50-2.19 ; \mathrm{p}=0.002)$ and high $\mathrm{IFG}$ $(\mathrm{OR}=1.70 ; 95 \%$ of $\mathrm{CI}=1.38-2.08 ; \quad \mathrm{P}=0.010)$ were independent factors as compared to normal glucose level. This result was also supported by Suleiman et al. 9 that diabetes mellitus (DM) $[\mathrm{OR}=2.6 ; 95 \%$ of $\mathrm{CI}=1.3-5.0$; $\mathrm{p}=0.004$ ) were independent predictor of 30 -days cardiovascular death and heart failure as compared to normal 
glucose level. Nau et al. ${ }^{19}$ found FG as independent predictors of in hospital major adverse cardiac events (death, reinfarction and heart failure) of acute MI patients $(\mathrm{OR}=1.03 ; 95 \%$ of $\mathrm{CI}=3.46-46.92 ; \mathrm{p}=0.001)$ as compared to that of admission glycaemia.

In this study, the patient with acute myocardial infarction with diabetes mellitus (DM) was a predictor for 30 days cardiovascular (CV) mortality as compared to euglycaemia [(Odd Ration $(\mathrm{OR})=8.167 ; 95 \%$ of confidence interval $(\mathrm{CI})=1.609-41.458 ; \mathrm{p}=0.011]$ and those with

impaired fasting glycaemia (IFG) was also a significant predictor for 30 days $\mathrm{CV}$ mortality as compared to euglycaemia $\quad(\mathrm{OR}=6.533 ; \quad 95 \% \quad$ of $\quad \mathrm{CI}=1.087-39.257$; $\mathrm{p}=0.040$ ). This result was supported by Verges et al.11 that $\mathrm{DM}[\mathrm{OR}=2.64 ; 95 \%$ of $\mathrm{CI}=1.93-3.62)]$ and high $\mathrm{IFG}$ $[\mathrm{OR}=2.33 ; 95 \%$ of $\mathrm{CI}=1.55-3.48)]$ were independent predictors of 30-days cardiovascular mortality as compared to normal glucose level. This result was also supported by Suleiman et al. ${ }^{9}$ that DM [OR $=10.295 \%$ of $\mathrm{CI}=4.4-23.7) ; \mathrm{p}<0.0001]$ and IFG $[4.0 ; 95 \%$ of $\mathrm{CI}=1.5$ 10.5); $\mathrm{p}=0.004]$ were independent predictors of 30-days cardiovascular mortality as compared to normal glucose level. Vivas et al. ${ }^{18}$ found FPG level was an independent risk factor for death or reinfarction $(126-200 \mathrm{mg} / \mathrm{dL}$, odds ratio $[\mathrm{OR}]=5.26$; $95 \%$ confidence interval $[\mathrm{CI}]=1.09$ $25.45 ;>200 \mathrm{mg} / \mathrm{dL}, \mathrm{OR}=6.66 ; 95 \%$ of $\mathrm{CI}=1.02-1.08$; $\mathrm{p}-0.02)$ as compared to that of admission glycaemia.

\section{Conclusion :}

The patients of hyperglycaemic group had 8.3 times more likely to develop acute left ventricular failure and 7.5 times more likely to had 30 days cardiovascular mortality as compared to that of euglycaemic group.

The patients of impaired fasting glycaemia and diabetes mellitus both were predictor for in hospital heart failure as compared to euglycaemia. The measurement of a fasting blood glucose level provides additional information in identify high-risk group of post-infarction patients.

\section{References:}

1. Selvin E, Marinopoulos, S, Berkenblit G, Rami T, Brancati Fl, Powe NR, et al. Meta-analysis: glycosylated hemoglobin and cardiovascular disease in diabetes mellitus. Ann Intern Med 2004; $141 ; 421-31$.
2. National Cholesterol Education Program (NCEP) Expert Panel on Detection, Evaluation, and Treatment of High Blood Cholesterol in Adults (Adult Treatment Panel iii). Third Report of the National Cholesterol Education Program (NCEP) Expert Panel on Detection, Evaluation and Treatment of High Blood Cholesterol in Adults (Adult Treatment Panel iii) final report. Circulation 2002; 106; 3143-221.

3. Ryden L, Standl E, Bartnik M, Van den Berghe G, Betteridge J, de Boer Mj, et al. Task Force on Diabetes and Cardiovascular Disease of the European Society of Cardiology (ESC(, European Association for the Study of Diabetes (EASD), Guidelines on diabetes, pre-diabetes and cardiovascular disease: executive summary. Eur Heart J 2007; 28:88-136.

4. Mozaffarian D, Marfisi R, Levantesi G, Valagussa F, Marchioli R. Incidence of new-onset diabetes and impaired fasting glucose in patients with recent myocardial infarction and the effect of clinical and lifestyle risk factors. Lancet 2007; 370:667-75.

5. Norhammar A, Tenerz A, Nilsson G, Hamsten A, Efendic S, Ryden $\mathrm{L}$, et al K. Glucose metabolism in patients with acute myocardial infarction and no previous diagnosis of diabetes mellitus: a prospective study. Lancet 2002; 359: 2140-4.

6. Hashimoto K, Ikewaki K, Yagi H, Nagaswa H, Imamoto S, Shibata T, Mochizuki S. Glucose intolerance is common in Japanese patients with acute coronary syndrome who were not previously diagnosed with diabetes. Diabetes Care 2005; 28:1182-6.

7. Capes SE, Hunt D, Malmberg K, Gerstein HC. Stress hyperglycaemia and increased risk of death after myocardial infarction in patients with and without diabetes: a systematic overview. Lancet $2000 ; 773-8$.

8. Oliver, M.F., Opie, L.H. Effects of glucose and fatty acids on myocardial ischaemia and arrhythmias. Lancet 1994; 343:155-8.

9. Suleiman M, Hammerman, H, Boulos M, Kapeliovich Mr, Suleiman A, Agmon Y, et al. Fasting glucose is an important independent risk factor for 30-day mortality in patients with acute myocardial infarction: a prospective study. Circulation 2005; 111:754-60.

10. Aronson D, Hammerman H, Kapeliovich Mr, Suleiman A, Agmon $\mathrm{Y}$, Beyar R. et al. Fasting glucose in acute myocardial infarction: incremental value for long-term mortality and relationship with left ventricular systolic function. Diabetes Care 2007; 30; 960-6.

11. Verges B, Zeller M, Dentan G, Beer JC, Laurent Y, Makki H, et al. Impact of Fasting Glycemia on Short-Term Prognosis after Acute Myocardial Infarction. J Clin Endocrinol Metab 2007; 92: 2136-40.

12. Porter A, Assali Ar, Zahalka A, lakobishvili Z, Brosh D, Lev El, et al. Impaired fasting glucose and outcomes of ST-elevation acute coronary syndrome treated with primary percutaneous intervention among patients without previously known diabetes mellitus. Am Heart J 2008; 155:284-9.

13. Zaman MM, Ahmed J, Choudhury SR, Numan SM, Parvin K, Islam MS. Prevalence of ischemic heart disease in a rural population of Bangldesh. Indian Heart Journal 2007 59(3): 239-41.

14. Foo, K., Cooper, J, Deaner, A., Knight, C., Suliman, A., Ranjadayalan, K. and Timmis, A, D. A single serum glucose measurement predicts adverse outcomes across the whole range of acute coronary syndromes. Heart 2003; 89:512-6.

15. Ogbera AO, Fasanmade AO, Chinenye S, Akinlade A. Characterization of lipid parameters in diabetes mellitus- a Nigerian report.

- International Archives of Medicine 2009; 2:19.

16. Witteles RM, Tang WH, Jamali AH, Chu JW, 
MB. Insulin resistance in idiopathic dilated cardiomyopathy: a possible etiologic link. J Am Coll Cardiol 2004; 44:78-81.

17. Suskin N, McKelvie RS. Burns RJ, Latini R, Pericak D, Probstfield $\mathrm{J}$, et al. Glucose and insulin abnormalities relate to functional capacity in patients with congestive heart failure. Eur Heart J. 2000; 21:1368-75.

18. Ishihara M, Inoue I, Kawagoe T, Shimatani Y, Kurisu S, Nishioka
Impact of acute hyperglycemia on left ventricular function after reperfusion therapy in patients with a first anterior wall acute myocardial infarction. Am Heart J. 2003; 146:674-8.

19. Barakat K, Wells Z, Ramdhany S, Mills PG. Timmis AD. Bangladeshi patients present with non-classic features of acute myocardia infarciton and are treated less aggressively in east London, UK. Heart 2003; 89:276-9. 